\title{
A modified Jarnagin-Blumgart classification better predicts survival for resectable hilar cholangiocarcinoma
}

\author{
Guoping Ding ${ }^{\dagger}$, Yifei Yang ${ }^{\dagger}$, Liping Cao*, Wenchao Chen, Zhengrong Wu and Guixing Jiang
}

\begin{abstract}
Background: Prediction of postoperative survival for hilar cholangiocarcinoma (HCCA) remains difficult although there have been a variety of clinical classification and staging systems. This study was designed to validate and compare some of the major HCCA staging systems in use today. In addition, we sought to build up a new staging system modified from Jarnagin-Blumgart (J-B) classification for HCCA, to predict survival better.
\end{abstract}

Methods: A total of 154 consecutive cases of HCCA including 95 surgical patients between 2005 and 2014 were enrolled in this study. The clinical and pathological data were recorded retrospectively and three commonly used classification methods: Bismuth-Corlette (B-C) classification, TNM staging, and J-B classification were performed to analyze the correlations with resectability and survival. Chi-square test, Kaplan-Meier analysis, and kappa statistics were used to compare and confirm the relationships between the variables and survival.

Results: For all 154 patients, the resection rate of J-B T1 was 68.6\% (48/70), higher than that of J-B T2 (44.8\%, $P=0.007)$. J-B T2 also showed a higher resectability than J-B T3 $(19.2 \%, P=0.025)$. There was no significant difference in resectability within the groups $\mathrm{B}-\mathrm{C}$ type and TNM stages. We set up a new staging system based on J-B classification, tumor differentiation, distant metastasis (N2 or M1 of TNM stage), and resection integrality. The total survival predictive accuracy was $69.5 \%$ (kappa $=0.547$ ), higher than that of TNM staging and J-B classification.

Conclusions: J-B classification was more useful than B-C classification, while its value for predicting survival did not exceed TNM staging system. The new staging system, based on J-B classification, provides a better method to stratify HCCA patients during the operation.

Keywords: Hilar cholangiocarcinoma, Stage, Survival, Jarnagin-Blumgart classification

\section{Background}

Hilar cholangiocarcinoma (HCCA), which occurs at or near the junction of the left and right hepatic ducts, still remains a difficult clinical problem for surgeons because of its low resectability and poor prognosis [1]. Radical resection is the only potentially curative therapy for HCCA. Most patients with untreated HCCA have a median survival of 6 months [2]. Even for patients who underwent radical resections, the 5-year survival rate is only about $20 \%$ to $40 \%[3,4]$. In recent years, surgical treatment of HCCA was more common than ever and

\footnotetext{
*Correspondence: cao@zju.edu.cn

${ }^{\dagger}$ Equal contributors

Department of Surgery, Second Affiliated Hospital, School of Medicine, Zhejiang University, Hangzhou 310009, China
}

the resection extent gradually expanded [5], while the staging and classification methods for HCCA fallen behind the surgical development. It still remains urgent to better stratify HCCA patients, paying more attention to long-term survival and low morbidity after operation.

At present, there exist a variety of clinical classification and staging systems for HCCA, including BismuthCorlette (B-C) classification [6], TNM staging of AJCC [7] and Jarnagin-Blumgart (J-B) classification [8], and so on. However, their criteria varied greatly and the prognostic accuracy has been questioned $[9,10]$. The mostly used B-C classification, which defines the longitudinal tumor spread along the bile duct, is inadequate for preoperative staging and predicting resectability. TNM staging system, which is based largely on pathological 
criteria, is a postoperative staging system and has little applicability for predicting resectability. As a preoperative clinical staging system, J-B classification is based on the factors related to local tumor extent within the hepatic portal and stratifies patients using noninvasive preoperative imaging. In a cohort of $380 \mathrm{HCCA}$ patients at Memorial Sloan-Kettering Cancer Center (MSKCC), J-B classification predicted the resectability with a convincing accuracy and the resectability significantly decreased with increasing clinical $\mathrm{T}$ stage. Unsatisfactorily, this staging system was less useful for predicting survival [11].

It is clearly understandable and predictable that the prognosis of unresectable HCCA is extremely poor, while there was no practical staging system which was specially designed for potential resectable HCCA. This study was designed to validate and compare some of the major HCCA staging systems in use today, thus to evaluate their clinical value for predicting resectability and survival of HCCA after resection. In addition, we sought to build up a new staging system based on J-B classification and the risk factors associated with survival, which will compensate the defect of J-B classification in predicting survival.

\section{Patients and methods}

\section{Ethics statement}

The research protocol was reviewed and approved by the Research Ethics Committee of Second Affiliated Hospital, School of Medicine, Zhejiang University. All participants or their guardians gave written consent of their serum samples and medical information to be used for scientific research.

\section{Patients}

From January 2005 to January 2014, a group of 154 consecutive HCCA patients, including 80 males (51.9\%) and 74 females $(48.1 \%)$ with a mean age of 62.3 years, were enrolled in the study. The patients were histologically confirmed of HCCA without previous or coexisting cancer.

There were 95 patients who underwent surgical treatments, including 56 males (58.9\%) and 39 females (41.1\%) with a mean age of 60.4 years (ranging from 29 to 84 years). Among the 95 HCCA patients, 61 cases (64.2\%) underwent a R0 resection including 16 cases of left hepatectomy, 7 cases of right hepatectomy, 5 cases of quadrate hepatectomy, and 4 cases of left and caudate lobe resection (complete resection of the tumor, regional lymph nodes dissection); 18 patients (18.9\%) underwent palliative resection (R1/R2, hepatic duct, and intestinal anastomosis); 3 patients (3.2\%) underwent tumor biopsy and internal drainage (R2 resection); and 13 patients (13.7\%) underwent surgical exploration and biopsy ( $R 2$ resection).

\section{Methods}

Clinical and pathological data of patients were reviewed retrospectively and analyzed according to the NCCN Guidelines for hepatobiliary cancer [12]. The tumor location, portal vein involvement, and hepatic lobe atrophy were evaluated by preoperative radiographic examinations. Tumor invasion depth, lymph node (LN) involvement, and distant metastasis were determined by postoperative pathological examinations. B-C classification, TNM stage, and J-B classification were evaluated for each patient.

Table 1 Analysis of staging method and surgical treatment

\begin{tabular}{|c|c|c|c|c|c|c|}
\hline & \multicolumn{5}{|c|}{ Surgical treatment $(n)$} & \multirow[t]{2}{*}{$P$} \\
\hline & Radical resection & Palliative resection & Internal drainage & Surgical exploration & Nonsurgical treatment & \\
\hline B-C classification ( $n$ ) & & & & & & 0.000 \\
\hline । & 19 & 5 & 0 & 2 & 12 & \\
\hline$\|$ & 17 & 2 & 0 & 0 & 14 & \\
\hline III & 24 & 10 & 2 & 3 & 26 & \\
\hline IV & 1 & 1 & 1 & 8 & 7 & \\
\hline TNM stage $(n)$ & & & & & & 0.000 \\
\hline । & 26 & 0 & 0 & 0 & & \\
\hline$\|$ & 25 & 5 & 1 & 1 & & \\
\hline III & 9 & 12 & 0 & 4 & & \\
\hline IV & 1 & 1 & 2 & 8 & & \\
\hline J-B classification ( $n$ ) & & & & & & 0.000 \\
\hline $\mathrm{T} 1$ & 38 & 10 & 0 & 2 & 20 & \\
\hline $\mathrm{T} 2$ & 21 & 5 & 1 & 2 & 29 & \\
\hline $\mathrm{T} 3$ & 2 & 3 & 2 & 9 & 10 & \\
\hline
\end{tabular}


Table 2 Analysis of variables correlated with overall survival of HCCA

\begin{tabular}{|c|c|c|c|c|c|c|}
\hline \multirow[t]{2}{*}{ Variables } & \multicolumn{4}{|c|}{ Survival time (years) } & \multirow[t]{2}{*}{ Chi-square } & \multirow[t]{2}{*}{$P$ value } \\
\hline & $\leq 1$ & $1 \sim 3$ & $3 \sim 5$ & $>5$ or alive & & \\
\hline $\operatorname{Sex}(n)$ & & & & & 6.29 & 0.098 \\
\hline Male & 13 & 25 & 0 & 11 & & \\
\hline Female & 14 & 18 & 5 & 9 & & \\
\hline Ages ( $n$, years) & & & & & 7.37 & 0.599 \\
\hline$\leq 40$ & 0 & 0 & 0 & 1 & & \\
\hline 40 to 60 & 11 & 20 & 3 & 7 & & \\
\hline 60 to 80 & 15 & 23 & 2 & 12 & & \\
\hline 80 and above & 1 & 0 & 0 & 0 & & \\
\hline Upper abdominal pain $(n)$ & & & & & 4.19 & 0.242 \\
\hline No & 10 & 24 & 4 & 10 & & \\
\hline Yes & 17 & 19 & 1 & 10 & & \\
\hline Jaundice $(n)$ & & & & & 3.69 & 0.297 \\
\hline No & 11 & 18 & 1 & 4 & & \\
\hline Yes & 16 & 25 & 4 & 16 & & \\
\hline Cholangiolithiasis ( $n$ ) & & & & & 1.62 & 0.655 \\
\hline No & 24 & 41 & 5 & 18 & & \\
\hline Yes & 3 & 2 & 0 & 2 & & \\
\hline Tumor differentiation $(n)$ & & & & & 23.48 & 0.001 \\
\hline Well & 10 & 19 & 4 & 14 & & \\
\hline Moderate & 5 & 19 & 1 & 6 & & \\
\hline Poor & 12 & 5 & 0 & 0 & & \\
\hline Margin status (n) & & & & & 50.91 & 0.000 \\
\hline RO resections & 3 & 33 & 5 & 20 & & \\
\hline $\mathrm{R} 1$ resections & 4 & 3 & 0 & 0 & & \\
\hline $\mathrm{R} 2$ resections & 20 & 7 & 0 & 0 & & \\
\hline LN involvement $(n)$ & & & & & 26.19 & 0.000 \\
\hline No & 12 & 38 & 5 & 19 & & \\
\hline N1 & 8 & 4 & 0 & 0 & & \\
\hline N2 & 7 & 1 & 0 & 1 & & \\
\hline Distant metastasis ( $n$ ) & & & & & 27.08 & 0.000 \\
\hline Mo & 16 & 42 & 5 & 20 & & \\
\hline M1 & 11 & 1 & 0 & 0 & & \\
\hline B-C classification ( $n$ ) & & & & & 13.02 & 0.162 \\
\hline I & 4 & 14 & 1 & 9 & & \\
\hline$\|$ & 4 & 6 & 2 & 3 & & \\
\hline III & 6 & 13 & 2 & 3 & & \\
\hline IV & 13 & 10 & 0 & 5 & & \\
\hline TNM staging $(n)$ & & & & & 47.27 & 0.000 \\
\hline I & 2 & 11 & 1 & 12 & & \\
\hline$\|$ & 4 & 18 & 4 & 6 & & \\
\hline III & 10 & 13 & 0 & 2 & & \\
\hline IV & 11 & 1 & 0 & 0 & & \\
\hline
\end{tabular}


Table 2 Analysis of variables correlated with overall survival of HCCA (Continued)

\begin{tabular}{|c|c|c|c|c|c|c|}
\hline J-B classification (n) & & & & & 33.79 & 0.000 \\
\hline $\mathrm{T} 1$ & 6 & 25 & 4 & 15 & & \\
\hline $\mathrm{T} 2$ & 8 & 16 & 1 & 5 & & \\
\hline T3 & 13 & 2 & 0 & 0 & & \\
\hline
\end{tabular}

The survival time was defined as the time between the date of surgery and the date of either death or last contact. According to the survival time, patients were divided into the following three groups: poor prognosis, 12 months or less; moderate prognosis, 12 to 36 months; and good prognosis, above 3 years.

\section{Statistics analysis}

All the clinical data were analyzed by the software of PASW statistics for windows (Version 18.0, SPSS Inc., Chicago, IL, USA). Numeration data were expressed as mean \pm SD. Survival was analyzed by Kaplan-Meier analysis. Chi-square test was used to confirm the relationship between the variables and survival. The agreement between tumor stage and actual survival was analyzed by means of kappa statistics.

\section{Results}

\section{Staging and surgical treatment}

The distribution of all the patients by B-C classification, TNM stage, and J-B classification is shown in Table 1. The resection rates (radical resection and palliative resection) of B-C types I, II, III, and IV were $63.2 \%$ (24/
38), 57.6\% (19/33), 52.3\% (34/65), and 11.1\% (2/18), respectively (Table 1$)$. There was no significant difference in resectability between B-C types I, II, and III $(P=0.558)$, although the B-C classification was correlated with surgical treatment. In this study, 59 patients (38.3\%) who accepted nonsurgical treatment were unable for TNM staging. The resection rates were $100 \%(26 / 26)$, 93.8\% (30/32), 84\% (21/25), and 16.7\% (2/12) for TNM stages I, II, III, and IV, respectively. There was also no significant difference between TNM stages I, II, and III $(P=0.085)$. For all 154 patients, the resection rate of $\mathrm{J}-\mathrm{B}$ T1 was $68.6 \%$ (48/70), higher than that of J-B T2 (44.8\%, $P=0.007)$. J-B T2 also showed a higher resectability than J-B T3 $(19.2 \%, P=0.025)$.

Among the 95 HCCA patients, 61 cases underwent a R0 resection including 32 cases of combined hepatectomy. The other 29 cases underwent a major bile duct excision and lymphadenectomy with negative bile duct margins, including 19 cases of B-C type I and 10 cases of type II. For the 61 patients who underwent R0 resections, the mean removed LN count was 9.3 (ranging from 3 to 25) and there were 10 cases with LN metastasis. The total LN metastasis rate was 22.1\% (21/95).

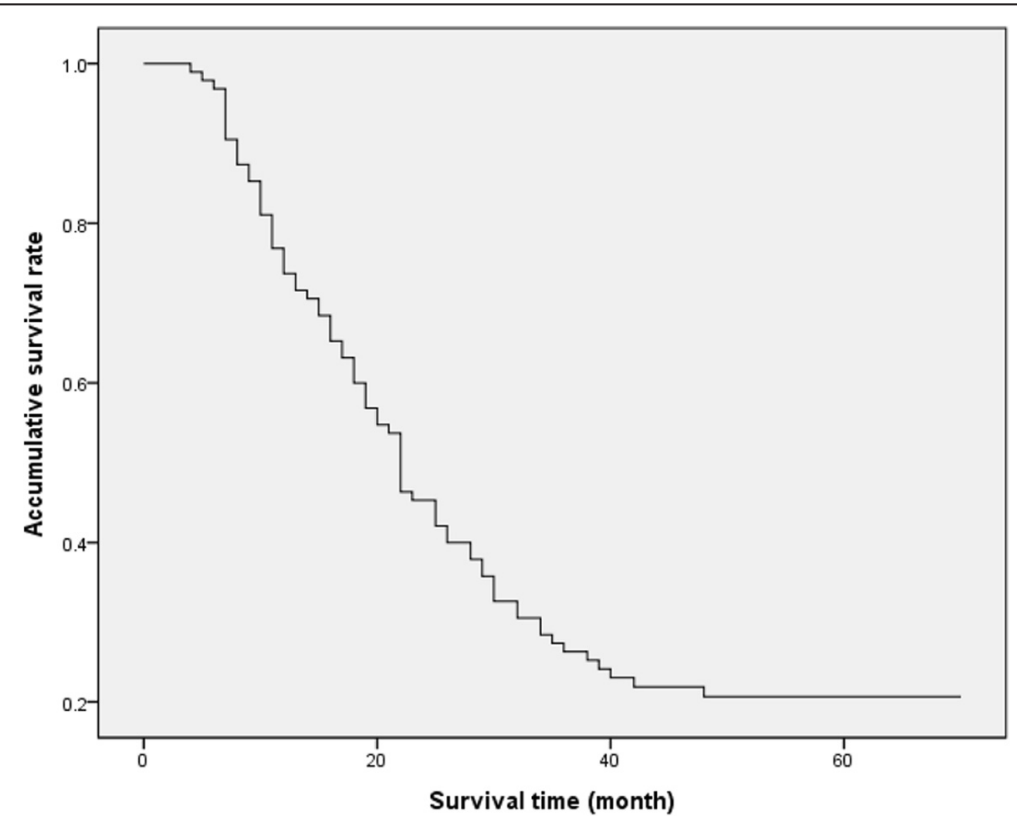

Figure 1 Survival curve of 95 HCCA patients after surgical treatment. The median survival time for all the 95 HCCA patients was 21.5 months. The 1-, 3-, and 5-year survival rates were $72 \%, 26 \%$, and $21 \%$, respectively. 


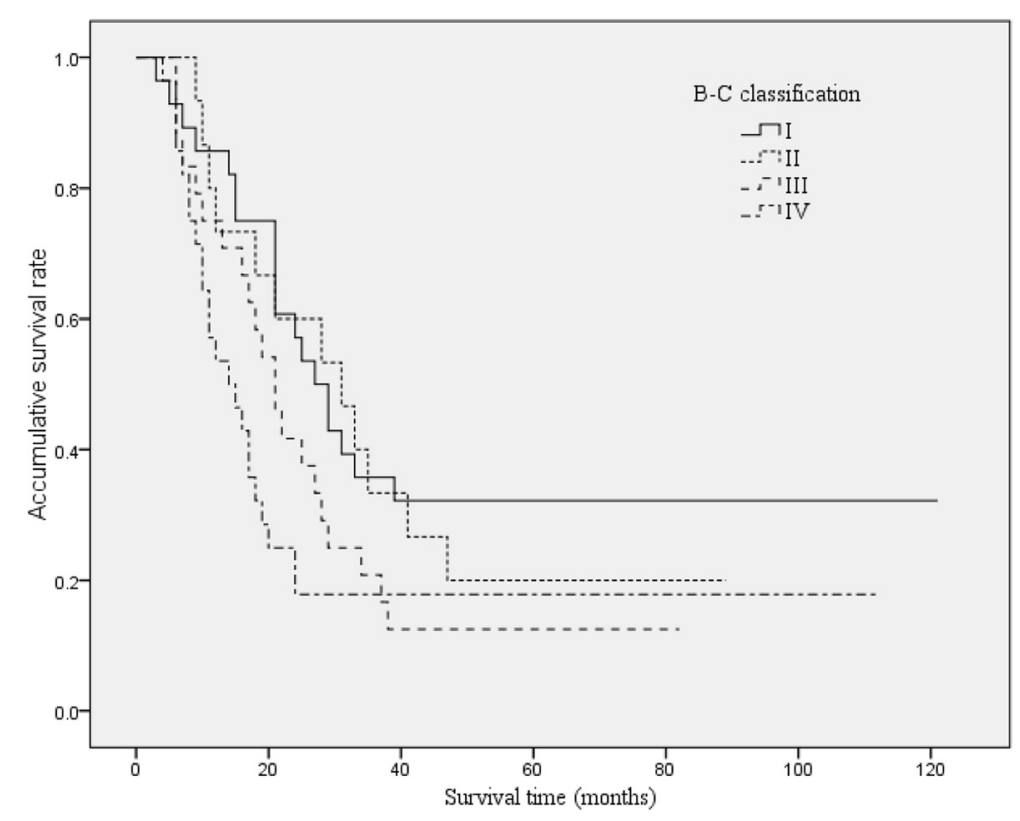

Figure 2 Overall Kaplan-Meier survival stratified by Bismuth-Corlette classification for HCCA. The median survival times were 27, 31, 21, and 14 months for B-C I, II III, and IV types, respectively.

\section{Clinical factors associated with survival}

To compare values of the three staging methods for predicting survival of HCCA, we analyzed the survival of 95 surgical patients. The main clinical and pathologic variables correlated with survival are shown in Table 2. The median survival time of was 21.5 months. The 1-, 3-, and 5-year accumulative survival rates were $72 \%, 26 \%$, and $21 \%$, respectively (Figure 1). The survival time of 75 patients who died ranged from 3 to 47 months, among which 27 (36\%) died in the first year after resection, 43 $(57.3 \%)$ died between 1 to 3 years, and $5(6.7 \%)$ died between 3 to 5 years. Chi-square test indicated that TNM stage, J-B classification, tumor differentiation, LN involvement, distant metastasis, and margin status were

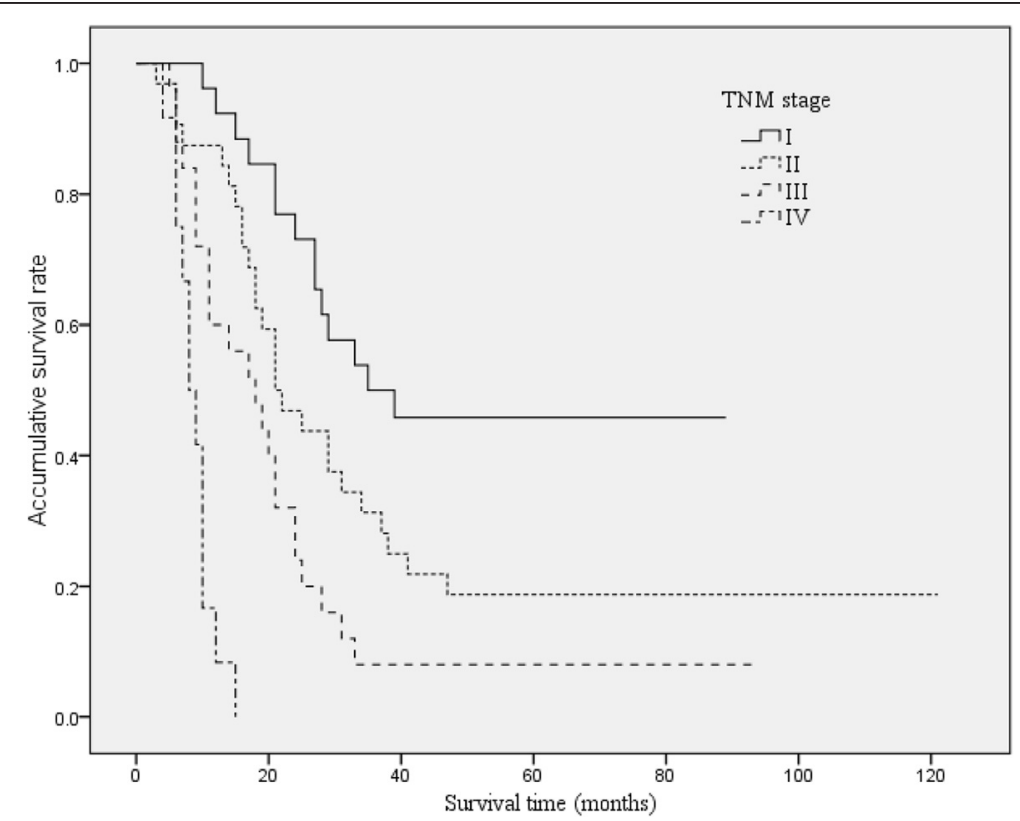

Figure 3 Overall Kaplan-Meier survival stratified by TNM stage for HCCA. The median survival times were 35, 21, 18, and 8 months for TNM I, II, III, IV stages, respectively. 


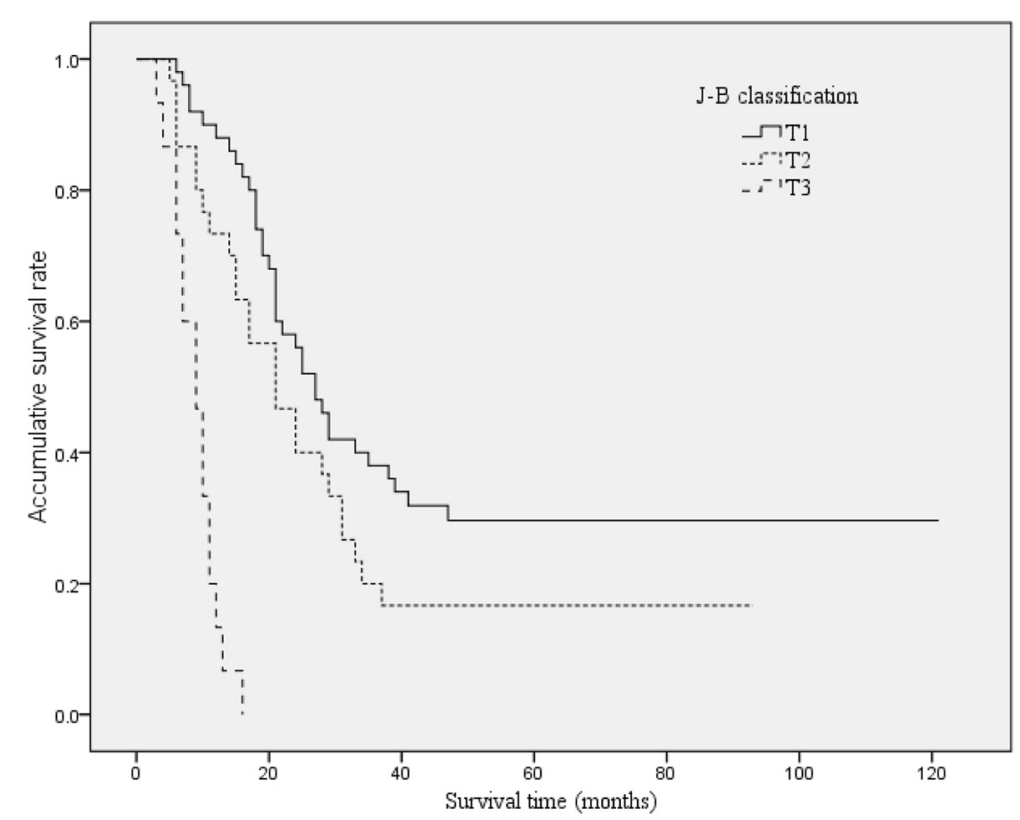

Figure 4 Overall Kaplan-Meier survival stratified by Jarnagin-Blumgart classification for HCCA. The median survival times were 27, 21, and 9 months for J-B T1, T2, and T3 stages, respectively.

significantly correlated with survival, while gender, age, upper abdominal pain, jaundice, and B-C classification were not (Table 1 ).

\section{The correlation of different classification methods and survival}

The survival curves of HCCA patients with different B-C classification, TNM stage, and J-B classification were shown in Figures 2, 3, and 4. The median survival time were $27,31,21$, and 14 months for B-C I, II, III, IV types; $35,21,18$, and 8 months for TNM I,

Table 3 Prediction of prognosis by the different staging system

\begin{tabular}{lllll}
\hline Stage & \multicolumn{2}{l}{ Prognosis $(\boldsymbol{n})$} & Accuracy (\%) \\
\cline { 2 - 3 } & Good & Moderate & Poor & \\
\hline TNM stage & 13 & 11 & 2 & 50.0 \\
I & 10 & 18 & 4 & 56.3 \\
II & 2 & 14 & 21 & 58 \\
J-B and IV & & & & \\
T1 & 19 & 25 & 6 & 38.0 \\
T2 & 6 & 16 & 8 & 53.3 \\
T3 & 0 & 2 & 13 & 86.7 \\
Modified J-B classification & & & & \\
I & 19 & 12 & 2 & 57.6 \\
II & 6 & 22 & 0 & 78.6 \\
III & 0 & 9 & 25 & 73.5 \\
\hline
\end{tabular}

II, III, IV stages; and 27, 21, and 9 months for J-B T1, T2, and T3 stages, respectively.

The predicting accuracies of TNM stage I for good prognosis, stage II for moderate prognosis, and stages III and IV for poor prognosis were $50.0 \%, 56.3 \%$, and $58 \%$ respectively (Table $3, P=0.000$, Kappa $=0.319$ ). The total predictive accuracy of TNM stage for prognosis of HCCA was $54.2 \%$. The predicting accuracies of J-B T1 for good prognosis, T2 for moderate prognosis, and T3 for poor prognosis were $38.0 \%, 53.3 \%$, and $86.7 \%$, respectively (Table 3, $P=0.000$, kappa $=0.266$ ). The total predictive accuracy of J-B classification was $50.5 \%$.

\section{The proposed staging system and survival}

By the statistic analysis of risk factors correlated with survival, we set up a new intraoperative staging system based on J-B classification which has a considerable value for predicting HCCA resectability. The staging system is shown in Tables 4 and 5 . The total score is calculated by adding the scores of preoperative J-B classification, intraoperative findings, and resection margin. The patients with

Table 4 The scoring criteria of the new staging system for hilar cholangiocarcinoma

\begin{tabular}{llll}
\hline Scores & $\begin{array}{l}\text { Jarnagin-Blumgart } \\
\text { classification }\end{array}$ & Intraoperative findings & $\begin{array}{l}\text { Resection } \\
\text { margin }\end{array}$ \\
\hline 0 & T1 & $\begin{array}{l}\text { High/moderate differentiation } \\
\text { without distant metastasis }\end{array}$ & R0 \\
1 & T2 & Poor differentiation & R1 \\
2 & T3 & Distant metastasis & R2 \\
\hline
\end{tabular}


Table 5 The proposed staging system and significance for hilar cholangiocarcinoma

\begin{tabular}{llll}
\hline Total score & Stage & Prognosis & Predicting survival time (years) \\
\hline 0 & I & Well & $>3$ \\
1 & II & Moderate & 1 to 3 \\
2 to 6 & III & Poor & $\leq 1$ \\
\hline
\end{tabular}

total scores of 0,1 , and $\geqq 2$ are considered as stage I, stage II, and stage III, respectively.

By this staging system, the median survival times were 41, 27, and 9 months for stages I, II, and III, respectively (Figure 5). The predicting accuracies of stage I for good prognosis, stage II for moderate prognosis, and stage III for poor prognosis were $57.6 \%, 78.6 \%$, and $73.5 \%$ respectively (Table $3, P=0.000$, kappa $=0.547$ ). The total predictive accuracy was $69.5 \%$, higher than that of TNM staging and J-B classification.

\section{Discussion}

HCCA is the most common type of cholangiocarcinoma, comprising up to $50 \%$ to $70 \%$ of all bile duct carcinomas [12]. The incidence of HCCA has increased over the past two decades, and the overall survival of HCCA is still extremely poor $[13,14]$. Even after a radical resection, the 5-year survival rate rarely exceeds $40 \%[3,4,15]$. A practical staging system, which can guide the optimal surgical treatment and predict postoperative survival with a convincing accuracy, is still urgently needed for surgeons [13]. In the present study, there were 61 cases (64.2\%) that underwent a R0 resection in 95 patients.
Major bile duct excision and lymphadenectomy with frozen section assessment of bile duct margins was performed for patients of B-C type I-II and without liver parenchyma involvement. Hilar bile duct resection with lymphadenectomy and combined hepatectomy was recommended for lesions of B-C type II-III or liver parenchyma involvement. The total LN metastasis rate was $22.1 \%$, and the median survival time was 21.5 months, which were similar to the previous studies $[16,17]$.

At present, there are a variety of clinical classification and staging methods for HCCA [6-8]. The B-C classification, which is commonly used for preoperative clinical classification of HCCA, does not include crucial information such as vascular involvement and distant metastases and therefore cannot identify nonresectable patients. Thus, it has been proved to have no correlation with resectability nor with survival [18]. The present study also showed that B-C classification had poor value for predicting resectability and survival. TNM staging system is the most common method for cancer staging, while its prognostic accuracy for HCCA has been questioned [9]. For HCCA, it seems inappropriate to define the $\mathrm{T}$ subgroups by transversal infiltration of tumor because the precise localization of the tumor infiltrated along the bile duct is crucial to present the natural history of the disease and predict survival, while it has not been included in the TNM staging system. In a study of 42 patients with cholangiocarcinoma, Zervos reported that the $\mathrm{T}$ subgroups were not associated with survival after resection [9]. Blumgart and Jarnagin proposed a preoperative staging system including three risk factors:

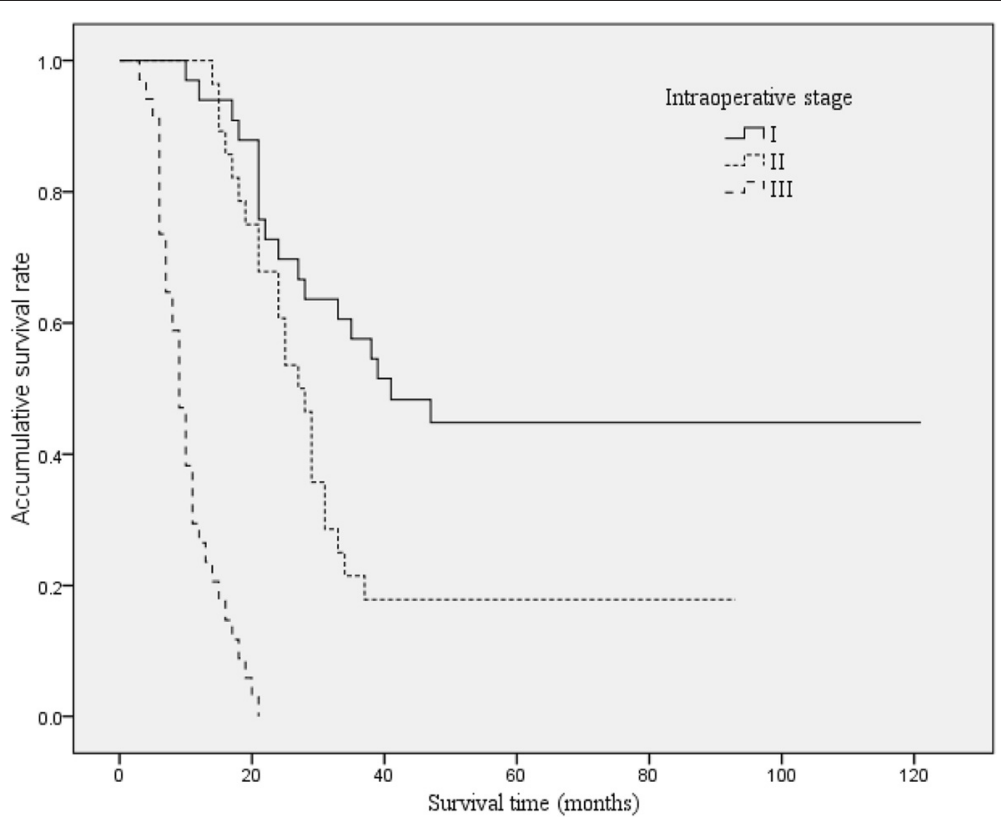

Figure 5 Overall Kaplan-Meier survival stratified by the new staging system for HCCA. By this staging system, the median survival times were 41,27 , and 9 months for stages I, II, and III, respectively. 
biliary duct involvement, vascular involvement, and lobe atrophy $[8,19]$. It was the first attempt to predict resectability of HCCA preoperatively and showed a convincing accuracy for preoperative staging of HCCA. In a study of 225 HCCA patients [19], resectability was nearly $60 \%$ in J-B T1 tumors, $31 \%$ in J-B T2 tumors, and $0 \%$ of J-B T3 tumors. J-B classification has been proved to be valuable for predicting resectability and survival, while it is still inadequate for full assessment of the tumor extent and does not exceed TNM staging system on accuracy of predicting survival. In a recent study of MSKCC, the median survival of J-B T1 and J-B T2 were 22.8 and 23.0 months, respectively, and there was no significant difference [11]. Our study showed the median survivals were 27, 21, and 9 months for J-B T1, T2, and T3 stages, respectively, similar to that of MSKCC. It seems difficult to differentiate the survival between the groups of J-B $\mathrm{T} 1$ and $\mathrm{T} 2$ stages.

So, it is still needed to better stratify the patients with potential resectable HCCA, guiding surgical treatment and predicting survival. For the purpose of setting up a practical staging system, we analyzed the correlations between clinicopathological variables and survival. The results showed that J-B classification, N2 LN involvement, distant metastasis, and tumor differentiation were risk factors correlated with survival. Consistent results have been reported in the previous studies $[13,15,19]$. We set the scoring system and staging criteria according to the following reasons: 1 . The total score of 2 to 6 was considered as stage III, which exists in the following conditions: J-B T3 stage or TNM IV stage or R2 resection. They are all indicators of poor survival less than 1 year. 2 . The patients with J-B T3 stage is considered as stage III and recommended for nonsurgical therapy by the J-B classification strategy. 3. Poor differentiation, J-B T2 stage, and R1 resection are labels of advance stage of tumor and predict poor survival $[6,20]$. So, the patients with one of the following risk factors, J-B T2 stage, poor differentiation, or R1 resection, have a poor survival and they were considered as stage II in the current staging system. The stage of modified J-B classification is determined after operation, more quickly than TNM staging system. Patients and their families can be informed immediately about the prognosis of the disease as soon as the operation is completed, which is helpful to alleviate their anxiety for postoperative prognosis.

Compared with another staging system which is proposed by the International Cholangiocarcinoma Group and specially designed for the staging of HCCA [21], our staging system is more easy to use and practical for surgeons. The new staging system showed considerable accuracy for predicting survival. The group of stage I had a significant higher survival rate than that of stage II. The total accuracy for predicting survival was $69.5 \%$, significantly higher than that of J-B classification and TNM staging system.

With the modified J-B staging system, it is still hard to predict the survival of the patients with a total score of 2 , although they were classified to stage III. The actual survival of these patients in the study ranged from 6 to 20 months, and $60 \%$ of them survived longer than 12 months. It is possible that these patients can obtain a longer survival by an aggressive treatment.

\section{Conclusions}

As a preoperative classification method, Jarnagin-Blumgart classification was more useful than B-C classification, while its value for predicting survival did not exceed TNM staging system. The new staging system, based on J-B classification, provides a better method to stratify HCCA patients during the operation. In the absence of effective adjuvant therapies for HCCA, the new intraoperative staging system will contribute to predict survival and guide surgical treatment.

\section{Abbreviations}

B-C: Bismuth-Corlette; HCCA: hilar cholangiocarcinoma; J-B: Jarnagin-Blumgart; MSKCC: Memorial Sloan-Kettering Cancer Center.

\section{Competing interests}

We declare that we have no financial and personal relationships with other people or organizations that can inappropriately influence our work. The authors declare that they have no competing interests.

\section{Authors' contributions}

GD was the main executant of the study. He collected the clinical data of all patients, participated in the statistical analysis, and prepared the manuscript. YY was a surgeon. He made the statistic analysis and drafted the manuscript. $L C$ is the leader of the research team. He designed the study, checked all the data, and provided technological supports for the study. WC is a graduate student. He helped Dr. Ding to collect the clinical data. ZW was a surgeon. He participated in the clinical management of patients with hilar cholangiocarcinoma. GJ was a surgeon. He helped Dr. Wu manage the patients with hilar cholangiocarcinoma. All authors read and approved the final manuscript. The first two authors had equal contributions to the study.

\section{Acknowledgments}

This research was supported by the Natural Science Foundation of China (81272671) and the Foundation of Science and Technology Department of Zhejiang Province, China (2011C13034-2).

Received: 7 October 2014 Accepted: 24 February 2015

Published online: 11 March 2015

\section{References}

1. Jemal A, Bray F, Center MM, Ferlay J, Ward E, Forman D. Global cancer statistics. CA Cancer J Clin. 2011;61:69-90.

2. Lau SH, Lau WY. Current therapy of hilar cholangiocarcinoma. Hepatobiliary Pancreat Dis Int. 2012;11:12-7.

3. Unno M, Katayose Y, Rikiyama T, Yoshida H, Yamamoto K, Morikawa T, et al. Major hepatectomy for perihilar cholangiocarcinoma. J Hepatobiliary Pancreat Sci. 2010;17:463-9.

4. Young AL, Prasad KR, Toogood GJ, Lodge JP. Surgical treatment of hilar cholangiocarcinoma in a new era: comparison among leading Eastern and Western centers, Leeds. J Hepatobiliary Pancreat Sci. 2010;17:497-504.

5. de Jong MC, Marques H, Clary BM, Bauer TW, Marsh JW, Ribero D, et al. The impact of portal vein resection on outcomes for hilar cholangiocarcinoma: a multi-institutional analysis of 305 cases. Cancer. 2012;118:4737-47. 
6. Bismuth $\mathrm{H}$, Nakache R, Diamond T. Management strategies in resection for hilar cholangiocarcinoma. Ann Surg. 1992;215:31-8.

7. Edge SB, Byrd DR, Compton CC, Fritz AG, Greene FL, Trotti A. Perihilar bile ducts. In: AJCC cancer staging handbook. 7th ed. Chicago, IL: Springer; 2010. p. 718.

8. Burke EC, Jarnagin WR, Hochwald SN, Pisters PW, Fong Y, Blumgart LH. Hilar cholangiocarcinoma: patterns of spread, the importance of hepatic resection for curative operation, and a presurgical clinical staging system. Ann Surg. 1998;228:385-94.

9. Zervos EE, Osborne D, Goldin SB, Villadolid DV, Thometz DP, Durkin A, et al. Stage does not predict survival after resection of hilar cholangiocarcinomas promoting an aggressive operative approach. Am J Surg. 2005;190:810-15.

10. Jarnagin WR, Ruo L, Little SA, Klimstra D, D'Angelica M, DeMatteo RP, et al. Patterns of initial disease recurrence after resection of gallbladder carcinoma and hilar cholangiocarcinoma: implications for adjuvant therapeutic strategies. Cancer. 2003;98:1689-700.

11. Matsuo K, Rocha FG, Ito K, D'Angelica Ml, Allen PJ, Fong Y, et al. The Blumgart preoperative staging system for hilar cholangiocarcinoma: analysis of resectability and outcomes in 380 patients. J Am Coll Surg. 2012;215:343-55.

12. Benson 3rd AB, Abrams TA, Ben-Josef E, Bloomston PM, Botha JF, Clary BM, et al. NCCN clinical practice guidelines in oncology: hepatobiliary cancers. J Natl Compr Canc Netw. 2009;7:350-91.

13. Khan SA, Thomas HC, Davidson BR, Taylor-Robinson SD. Cholangiocarcinoma. Lancet. 2005;366:1303-14.

14. Khan SA, Toledano MB, Taylor-Robinson SD. Epidemiology, risk factors, and pathogenesis of cholangiocarcinoma. HPB (Oxford). 2008;10:77-82.

15. Schiffman SC, Reuter NP, McMasters KM, Scoggins CR, Martin RC. Overall survival peri-hilar cholangiocarcinoma: R1 resection with curative intent compared to primary endoscopic therapy. J Surg Oncol. 2012;105:91-6.

16. Dinant S, Gerhards MF, Rauws EA, Busch OR, Gouma DJ, van Gulik TM. Improved outcome of resection of hilar cholangiocarcinoma (Klatskin tumor). Ann Surg Oncol. 2006;13:872-80.

17. Noji T, Miyamoto M, Kubota KC, Shinohara T, Ambo Y, Matsuno Y, et al. Evaluation of extra capsular lymph node involvement in patients with extra-hepatic bile duct cancer. World J Surg Oncol. 2012;10:106

18. Blechacz B, Komuta M, Roskams T, Gores GJ. Clinical diagnosis and staging of cholangiocarcinoma. Nat Rev Gastroenterol Hepatol. 2011;8:512-22.

19. Jarnagin WR, Fong Y, DeMatteo RP, Gonen M, Burke EC, Bodniewicz Bs J, et al. Staging, resectability, and outcome in 225 patients with hilar cholangiocarcinoma. Ann Surg. 2001;234:507-17.

20. Saxena A, Chua TC, Chu FC, Morris DL. Improved outcomes after aggressive surgical resection of hilar cholangiocarcinoma: a critical analysis of recurrence and survival. Am J Surg. 2011;202:310-20.

21. Deoliveira ML, Schulick RD, Nimura Y, Rosen C, Gores G, Neuhaus P, et al. New staging system and a registry for perihilar cholangiocarcinoma. Hepatology. 2011;53:1363-71.

\section{Submit your next manuscript to BioMed Central and take full advantage of:}

- Convenient online submission

- Thorough peer review

- No space constraints or color figure charges

- Immediate publication on acceptance

- Inclusion in PubMed, CAS, Scopus and Google Scholar

- Research which is freely available for redistribution 